\title{
TU/e EmonOWEN

\section{An artificial nocturnal flower via humidity-gated photoactuation in liquid crystal networks}

\section{Citation for published version (APA):}

Wani, O. M., Verpaalen, R., Zeng, H., Priimagi, A., \& Schenning, A. P. H. J. (2019). An artificial nocturnal flower via humidity-gated photoactuation in liquid crystal networks. Advanced Materials, 31(2), [1805985]. https://doi.org/10.1002/adma.201805985

\section{Document license: \\ TAVERNE}

DOI:

10.1002/adma.201805985

Document status and date:

Published: 11/01/2019

\section{Document Version:}

Publisher's PDF, also known as Version of Record (includes final page, issue and volume numbers)

\section{Please check the document version of this publication:}

- A submitted manuscript is the version of the article upon submission and before peer-review. There can be important differences between the submitted version and the official published version of record. People interested in the research are advised to contact the author for the final version of the publication, or visit the $\mathrm{DOI}$ to the publisher's website.

- The final author version and the galley proof are versions of the publication after peer review.

- The final published version features the final layout of the paper including the volume, issue and page numbers.

Link to publication

\section{General rights}

Copyright and moral rights for the publications made accessible in the public portal are retained by the authors and/or other copyright owners and it is a condition of accessing publications that users recognise and abide by the legal requirements associated with these rights.

- Users may download and print one copy of any publication from the public portal for the purpose of private study or research.

- You may not further distribute the material or use it for any profit-making activity or commercial gain

- You may freely distribute the URL identifying the publication in the public portal.

If the publication is distributed under the terms of Article 25fa of the Dutch Copyright Act, indicated by the "Taverne" license above, please follow below link for the End User Agreement:

www.tue.nl/taverne

Take down policy

If you believe that this document breaches copyright please contact us at:

openaccess@tue.nl

providing details and we will investigate your claim. 


\title{
An Artificial Nocturnal Flower via Humidity-Gated Photoactuation in Liquid Crystal Networks
}

\author{
Owies M. Wani, Rob Verpaalen, Hao Zeng, Arri Priimagi,* and Albert P. H. J. Schenning**
}

Beyond their colorful appearances and versatile geometries, flowers can self-shape-morph by adapting to environmental changes. Such responses are often regulated by a delicate interplay between different stimuli such as temperature, light, and humidity, giving rise to the beauty and complexity of the plant kingdom. Nature inspires scientists to realize artificial systems that mimic their natural counterparts in function, flexibility, and adaptation. Yet, many of the artificial systems demonstrated to date fail to mimic the adaptive functions, due to the lack of multi-responsivity and sophisticated control over deformation directionality. Herein, a new class of liquid-crystalnetwork (LCN) photoactuators whose response is controlled by delicate interplay between light and humidity is presented. Using a novel deformation mechanism in LCNs, humidity-gated photoactuation, an artificial nocturnal flower is devised that is closed under daylight conditions when the humidity level is low and/or the light level is high, while it opens in the dark when the humidity level is high. The humidity-gated photoactuators can be fueled with lower light intensities than conventional photothermal LCN actuators. This, combined with facile control over the speed, geometry, and directionality of movements, renders the "nocturnal actuator" promising for smart and adaptive bioinspired microrobotics.

Among these, smart materials provide great opportunities to control/manipulate micron-sized elements by using a wireless approach, thus providing huge potential for technological developments of tomorrow. ${ }^{[14,15]}$

Plants act as a vital source of inspiration for novel stimuli-responsive materials. ${ }^{[16-19]}$ Several factors dictate the plant movements, such as cell growth, turgor pressure, cohesion forces, or swelling/shrinking of the cell walls. ${ }^{[16]}$ In some cases, plant movements are triggered by mechanical contact, ${ }^{[20]}$ while shape morphing of some other plants correlates with environmental conditions such as light level, temperature, and humidity. The movements can be either active, in which case they rely on plant metabolism and require energy, or passive and predetermined by the plant structure, i.e., regulated by environmental conditions and not requiring living tissue. ${ }^{[21]}$ An intriguing example of plant movements is the opening and closing of flowers, in response to interplay between various stimuli. In many species,

The past decades have shown that technological advances often go hand in hand with the development of new materials. For seeking inspiration, material scientists and engineers put great effort into learning from nature's sophisticated design principles. ${ }^{[1-4]}$ For example, stimuli-responsive "smart" materials that reversibly change their shape in response to external triggers, pave way for soft robotics ${ }^{[5-7]}$ and self-regulating devices, ${ }^{[8-10]}$ and bioinspired hierarchical surfaces are pertinent in application in wettability control and adhesion. ${ }^{[11-13]}$

O. M. Wani, Dr. H. Zeng, Prof. A. Priimagi

Laboratory of Chemistry and Bioengineering

Tampere University of Technology

P.O. Box 541, Fl-33101 Tampere, Finland

E-mail: arri.priimagi@tut.fi

R. Verpaalen, Prof. A. P. H. J. Schenning

Laboratory of Stimuli-Responsive Functional Materials and Devices

Department of Chemical Engineering and Chemistry

Eindhoven University of Technology

P.O. Box 513, 5600 MB Eindhoven, The Netherlands

E-mail: a.p.h.j.schenning@tue.nl

The ORCID identification number(s) for the author(s) of this article can be found under https://doi.org/10.1002/adma.201805985.

DOI: 10.1002/adma.201805985 flower opening/closing is correlated with the time of day and temperature, and light and humidity play an important role in regulating the process. Flowers which bloom in the morning are mainly regulated by temperature and/or light, while in nocturnal flowers, relative humidity (RH) plays an additional role, and their opening correlates with both decrease in light intensity and increase in the RH. ${ }^{[22]}$ Being based on an interplay between different stimuli, the opening and closing of flowers highlights the versatile and adaptive behavior of plant species and more generally, the complexity of plant kingdom. This depicts that for realization of manmade devices capable of mimicking the complex functionalities of natural species, the use of multi-responsive materials is one of the key design principles.

Despite the significant research effort dedicated to stimuliresponsive materials and structures, ${ }^{[1,15]}$ multi-responsive materials that can be triggered by light, temperature, and humidity (or an interplay between them) have been rarely studied. Agarosebased hybrid materials containing acidochromic fluorophores or azobenzene derivatives have been demonstrated to undergo humidity- and light-induced deformations..$^{[23,24]}$ Carbon-nitridebased polymers that are sensitive to small fluctuations in humidity and that can quickly lose the absorbed water through heating or UV light irradiation, have also been fabricated. ${ }^{[25]}$ Finally, bilayer materials containing carbon nanotubes or reduced graphene 
oxide can also exhibit light- and humidity-induced bending movements by controlling water absorption/desorption via photothermal effect. ${ }^{[26,27]}$ However, these materials are either based on laminated bilayers, which restricts their practical utility, or they lack sophisticated control over the directionality of the movements, which is an important factor for developing biomimetic actuators. By using liquid crystal networks (LCNs), both of these deficiencies can be addressed. LCNs combine the anisotropic properties of liquid crystals with the mechanical rigidity of polymer networks, thereby providing stimuli-responsive anisotropic deformation of the network with movement direction governed by the alignment of the constituent LC molecules. ${ }^{[28,29]}$ As the molecular alignment can be controlled and even patterned during the fabrication process, LCN actuators can have many degrees of freedom in their deformation. ${ }^{[30,31]}$ The programmable, reversible shape changes render LCNs attractive from the perspective of soft actuators/robotics. ${ }^{[32]}$ By proper materials design, actuation in LCNs can be triggered by humidity changes, resulting in efficient bending with well-controlled directionality, in a monolithic structure. ${ }^{[33-35]}$ Up to date, the only example of LCN actuator driven by both light and humidity is given by Liu et al., [36] where they have demonstrated a dual-mode bending of LCN film either toward light source along the director axis, or away from humidity source perpendicular to the director axis. However, the multi-responsive LCN presented in ref. [36] was only actuated by either light or humidity, i.e., the two stimuli were orthogonal and not interconnected. Furthermore, the molecular alignment of that LCN was uniform throughout the sample, hence it responded to humidity gradient rather than to change in ambient humidity per se. For the creation of logical gates from multi-responsive actuators and evermore sophisticated bioinspired structures, it is pertinent to first understand the intricate interplay that may exist between the different stimuli, and then co-use them to introduce functionalities not met by the different stimuli alone. To the best of our knowledge, such interplay between light and humidity in LCN actuators has not been previously studied.

In the present work, we take inspiration from the nocturnal flower and devise a monolithic LCN actuator whose movements are controlled by a delicate interdependence between light and humidity, a process that we coin as humidity-gated photoactuation. Alike its natural counterpart, the nocturnal actuator opens under dark and humid conditions, and closes when the humidity decreases and light level increases (Figure 1a). Such unconventional actuation is based on selective absorption of water on one surface of the "flower petal," which closes upon photothermally-induced water desorption and resultant deswelling of the petals. We show that the deformation mechanism underlying the humidity-gated photoactuation, which has not been studied in LCN actuators before, greatly increases the sensitivity of the deformation, allowing the use of low light levels to trigger fast and efficient photoactuation.

To combine the humidity sensitivity and light response into one LCN actuator, we incorporated a "photothermal moiety," an azobenzene derivative Disperse Red 1 acrylate, into an LC mixture consisting of hydrogen-bonded, acrylate-based carboxylic acid monomers of varying chain lengths. ${ }^{[37]}$ The composition of the mixture is given in Figure 1b (see the "Materials and characterization" section in the Supporting Information). Polymerization (365 nm, $20 \mathrm{~mW} \mathrm{~cm} \mathrm{~cm}^{-2}, 5 \mathrm{~min}$ ) was performed in a $20 \mu \mathrm{m} \mathrm{LC}$ cell at a temperature of $80{ }^{\circ} \mathrm{C}$. The relatively high polymerization temperature was used in order to obtain high initial curvature for the LCN actuator at ambient conditions, and to avoid the formation of cybotactic clusters at lower temperatures (Figure S1, Supporting Information). ${ }^{[38]}$ The high initial curvature results from anisotropic thermal expansion of the film polymerized above room temperature: the more the difference between the polymerization temperature and room temperature, the larger the curvature (defined as the inverse radius). ${ }^{[10,39]}$ In terms of alignment, splayed molecular orientation was chosen because splay-aligned LCN actuators bend smoothly and to high degrees, ${ }^{[40]}$ and their bending axis can be manipulated by changing the angle between the long axis of the strip and the director on the planar side. ${ }^{[31]}$ The combination of suitable polymerization temperature and splay alignment render LCN strips capable of mimicking the geometry of a flower, together with the curvature change during flower blooming. After polymerization, the sample was soaked in a basic solution (0.1 M aq. solution of $\mathrm{KOH}$ ) to make it humidity sensitive. The base treatment breaks the hydrogen bonds between the carboxylic acid dimers and converts them into hygroscopic carboxylic salt. ${ }^{[34]}$ The treatment was selectively executed on the homeotropic side of the sample, to form a hygroscopic surface (Figure 1c). This was confirmed by ATR-FTIR spectra that showed the loss of hydrogen bonding peak and appearance of a peak corresponding to carboxylates on the homeotropic side of the sample, while no spectral change was observed on the planar surface (Figure S2, Supporting Information). In addition to making the material hygroscopic, the base treatment also causes further shrinkage of the $\mathrm{LCN}^{\left[{ }^{[34]}\right.}$ thereby leading to increase in the curvature of the strip. The treated LCN strip is now sensitive to both light and humidity and its initial shape depends on the $\mathrm{RH}$ and the angle between the director on planar side and the long axis of the strip.

Comparison of the photomechanical properties of the LCN actuator before and after the base treatment is shown in Figure 2. As expected, the untreated sample is indifferent to humidity change, but responds to light. Upon exposure to $450 \mathrm{~nm}\left(100 \mathrm{~mW} \mathrm{~cm}^{-2}\right)$, the strip opens (curvature decreases) due to photothermal expansion of the homeotropic surface caused by decrease in order in the LCN network (Figure 2a). After the base treatment, the curvature of the strip increases with humidity, due to absorption of water toward the homeotropic side of the strip. This humidity-induced shape-change is fully reversible upon variation in the RH. Under simultaneous stimuli of humidity and light irradiation, such dual-responsive LCN behaves in an interesting manner. At low RH, the basetreated strip slightly opens up and the curvature decreases, due to light-induced expansion of the homeotropic surface (Figure 2b). This is the normal photoactuation mechanism in splay-aligned LCNs. ${ }^{[30]}$ We note here that we observe a decrease in molecular order in the splay films after the base treatment, as evident from the polarized UV-vis absorption spectra shown in Figure S3 in the Supporting Information. This explains the fact that the photoactuation is less efficient in the base-treated films as compared to non-treated films when the humidity is low. At high $\mathrm{RH}$, the light response of the base-treated film becomes totally opposite. As illustrated in Figure 2b, the curvature of the strip increases (the strip closes), even upon low-intensity 

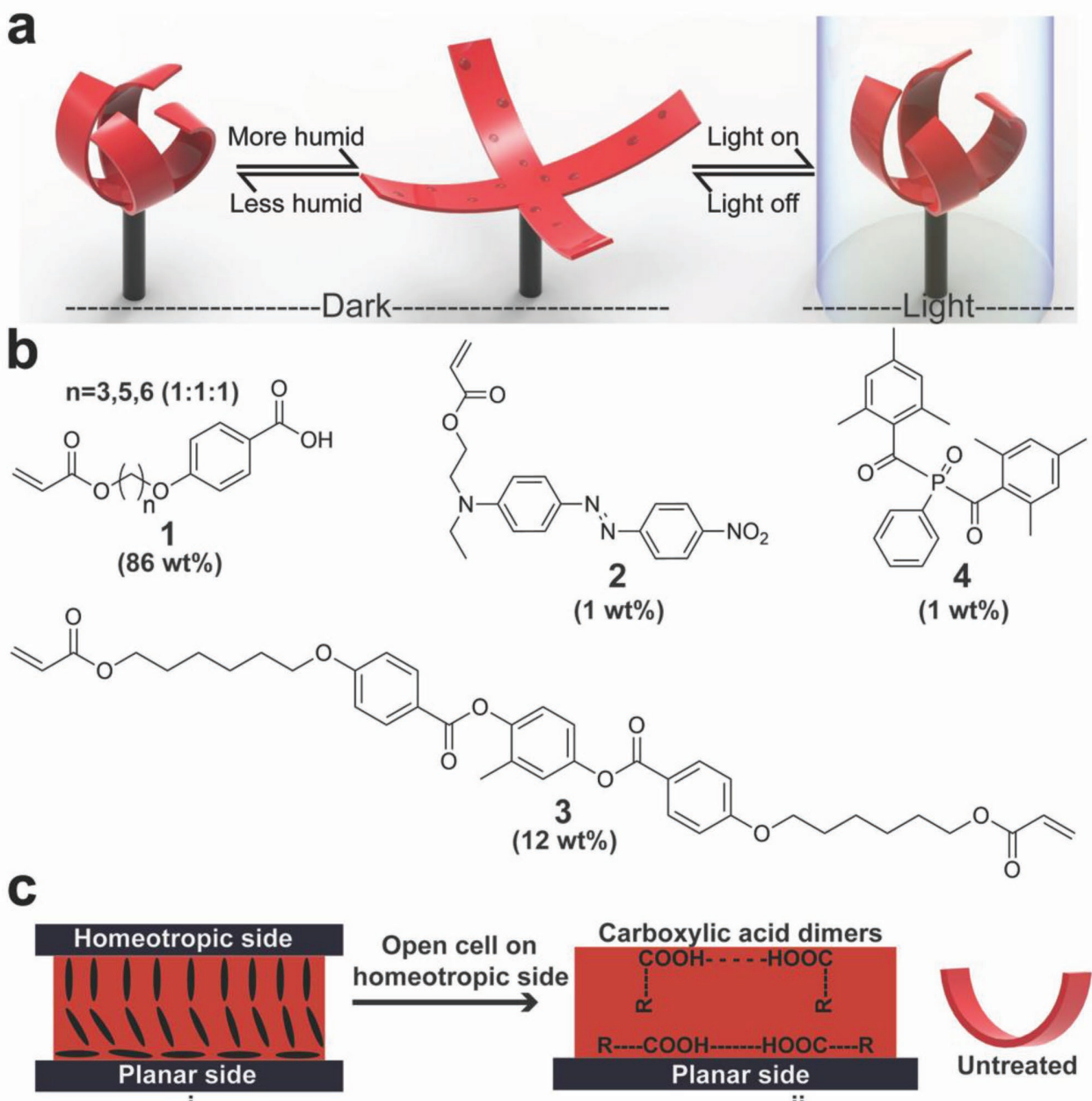

i
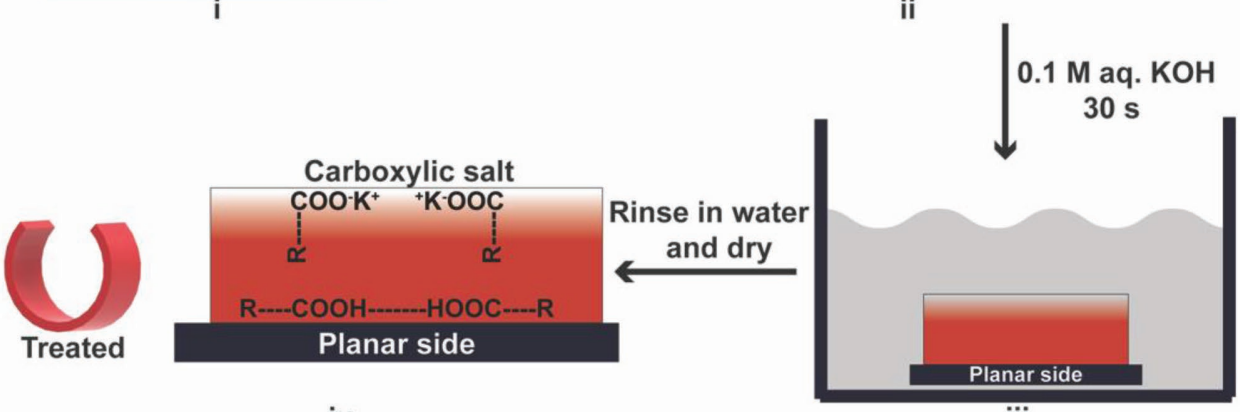

iv

iii

Figure 1. Realization of artificial nocturnal flower. a) Schematic representation of the nocturnal actuator: the flower opens at high humidity level in absence of light and closes in the presence of light or when the humidity is low. b) Composition of the LC mixture used in fabrication of the nocturnal actuator. c) The fabrication process: i) the mixture is polymerized in splay molecular alignment inside an LC cell, ii,iii) the cell is opened from the homeotropic side and dipped in $0.1 \mathrm{M} \mathrm{KOH}$ solution for $30 \mathrm{~s}$, to perform base treatment selectively on the homeotropic side, and iv) the sample is rinsed with water and then dried in air. The insets in (c-ii) and (c-iv) show the schematic representation of the LCN strips, cut along the director on the planar side, at corresponding stage of fabrication under ambient conditions.

irradiation (450 nm, $30 \mathrm{~mW} \mathrm{~cm}{ }^{-2}$ ). In other words, given proper humidity level, the light-induced bending in the splay-aligned LCN takes place toward the homeotropic side of the film. Such unconventional photoactuation, gated by humidity, forms the basis for mimicking the behavior of nocturnal flower. As we will show, the mechanism behind the humidity-gated photoactuation is completely different than in conventional photoactuators.
We next studied the effect of $\mathrm{RH}$ on the curvature of the multi-responsive LCN strip and its shape-change upon light exposure in more detail. The curvature of the strip decreased linearly with increasing RH (Figure 3a). ${ }^{[34]}$ When the strip is exposed to light under $80 \% \mathrm{RH}$, the curvature increases with increasing light intensity and saturates at $50-60 \mathrm{~mW} \mathrm{~cm} \mathrm{~cm}^{-2}$ (Figure 3b,c). We attribute the efficient photoactuation in 


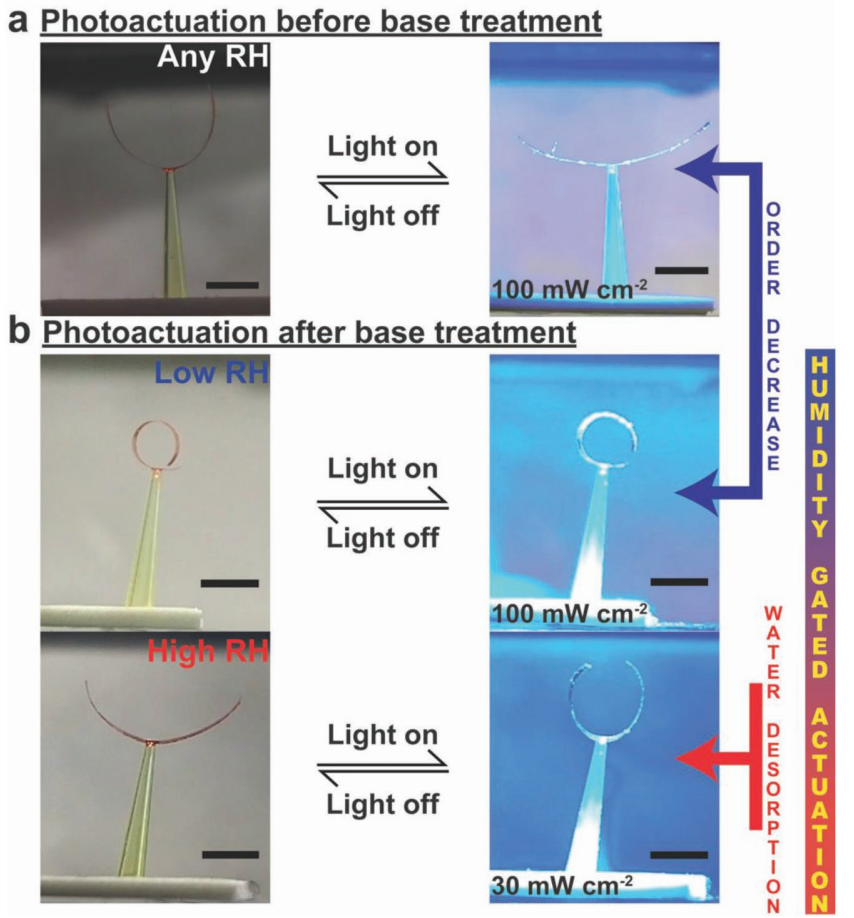

Figure 2. Humidity-gated photoactuation. a) Before base treatment, the LCN strip is insensitive to humidity and photoactuation results in expansion of homeotropic surface owing to decrease in molecular order. b) After base treatment, photoactuation is gated by humidity. At low $\mathrm{RH}$, the curvature decreases due to similar mechanism as mentioned in (a). However, at high $\mathrm{RH}$, the curvature increases owing to entirely different mechanism, i.e., light induced water desorption. All scale bars correspond to $5 \mathrm{~mm}$. Strip dimension: $20 \mathrm{~mm} \times 3 \mathrm{~mm} \times 20 \mu \mathrm{m}$. Light source: $450 \mathrm{~nm}$.

base-treated films to water desorption from the hygroscopic (homeotropic) surface, which results in selective shrinkage and bending toward the homeotropic surface. Such process is highly light-sensitive, much more so than conventional photothermal actuation (Figure 2b,c). Thus, the coupling between light and humidity leads to a thermodynamically favored actuation mode driven by photothermally-induced water loss. The rate of water desorption is affected by the light intensity. Therefore, the irradiation power dictates the speed of actuation. This is demonstrated in Figure S4 in the Supporting Information, which reveals an enhanced actuation speed upon increasing intensity: the response time drops from 9 to $1.8 \mathrm{~s}$ when changing the intensity from 60 to $160 \mathrm{~mW} \mathrm{~cm}{ }^{-2}$. The higher sensitivity of the base-treated samples to low-intensity irradiation may also be somewhat affected by decrease in storage modulus of material after base treatment (Figure S5, Supporting Information).

To confirm the mechanism of light-induced closing of the humidity-sensitive LCN strip, we used infrared spectroscopy to probe the loss of water inside the sample. The sample was kept under high humidity inside the spectrometer and the NIR absorption spectra were recorded at different temperatures (Figure S6, Supporting Information). The intensity of water absorption peak at around $1900 \mathrm{~nm}$ was used to probe the water content, alike in previous studies. ${ }^{[41,42]}$ The water content absorbed by the LCN decreased with increasing temperature within initial $10{ }^{\circ} \mathrm{C}$ temperature change (from 20 to

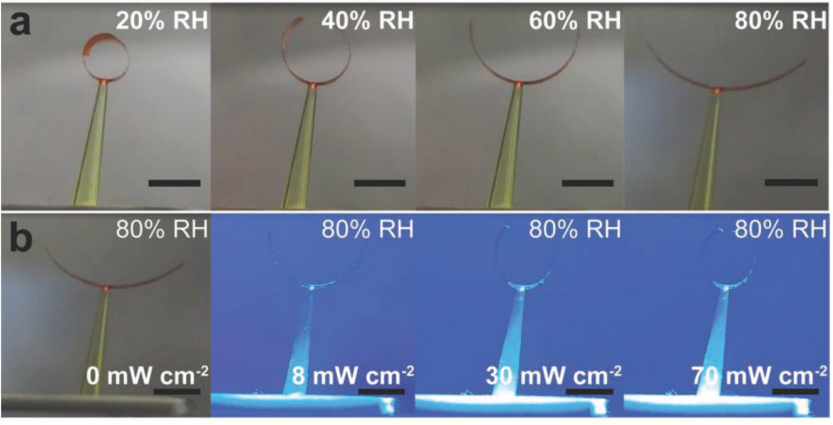

C

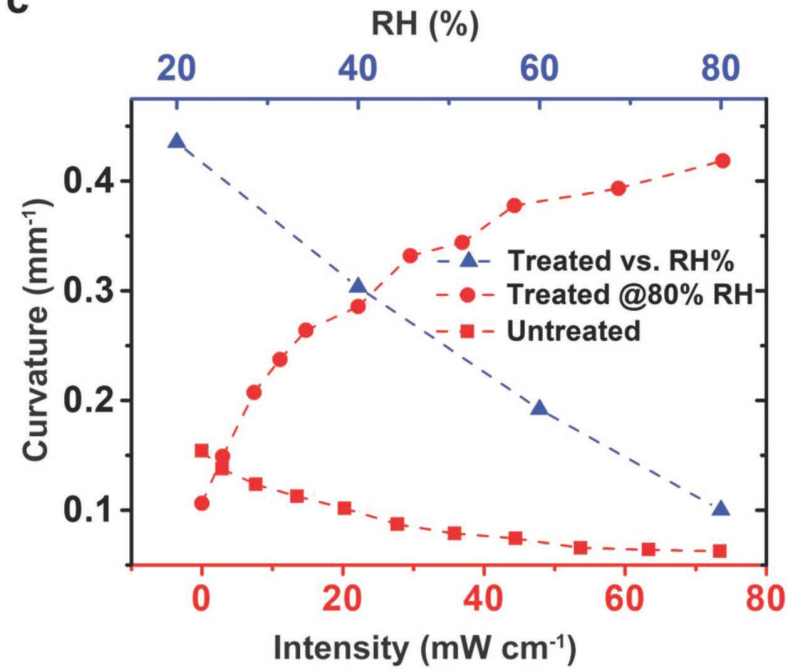

Figure 3. Curvature changes with variation in $\mathrm{RH}$ and light intensity. a) Change in curvature of treated LCN strip with increasing $\mathrm{RH}$, under dark conditions. b) Effect of light intensity on curvature of LCN strip held at $80 \% \mathrm{RH}$ (room temperature). c) Curvature changes of LCN strips in response to increasing $\mathrm{RH}$ in the dark (blue triangles), and the photoinduced curvature change of treated (red circles), and untreated (red squares) $\mathrm{LCN}$ strips held at $80 \% \mathrm{RH}$ in response to increasing light intensity. All scale bars correspond to $5 \mathrm{~mm}$.

$30{ }^{\circ} \mathrm{C}$ ), after which the water content saturated. Photothermal temperature rise in LCN strip, as measured by IR thermal camera, together with the curvature change upon increasing light intensity, is plotted in Figure 4a. Water loss upon increase in temperature, as estimated by NIR absorption, is plotted in Figure $4 \mathrm{~b}$. In addition to the fact that most of the water is evaporated within $10{ }^{\circ} \mathrm{C}$ temperature increase, the data shows that major change in curvature occurs with light intensity below 50-60 $\mathrm{mW} \mathrm{cm}^{-2}$. Infrared camera measurements reveal that 50-60 $\mathrm{mW} \mathrm{cm} \mathrm{cm}^{-2}$ irradiation causes the temperature of LCN strip to rise by $7-10^{\circ} \mathrm{C}$, which, based on probing the water loss, is enough for efficient reduction of water content and thereby, saturation of the photo-induced change in curvature.

To use the interplay between light-sensitivity and humiditysensitivity, and to demonstrate the nocturnal flower, we fabricated a monolithic piece of LCN having predesigned molecular alignment. The artificial flower consists of four petals, each bending toward the same central point. The alignment control was done using a substrate coated with polyimide alignment layer rubbed in two directions, using a steel-foil mask, to obtain the molecular orientation depicted in Figure 4c. Alike 

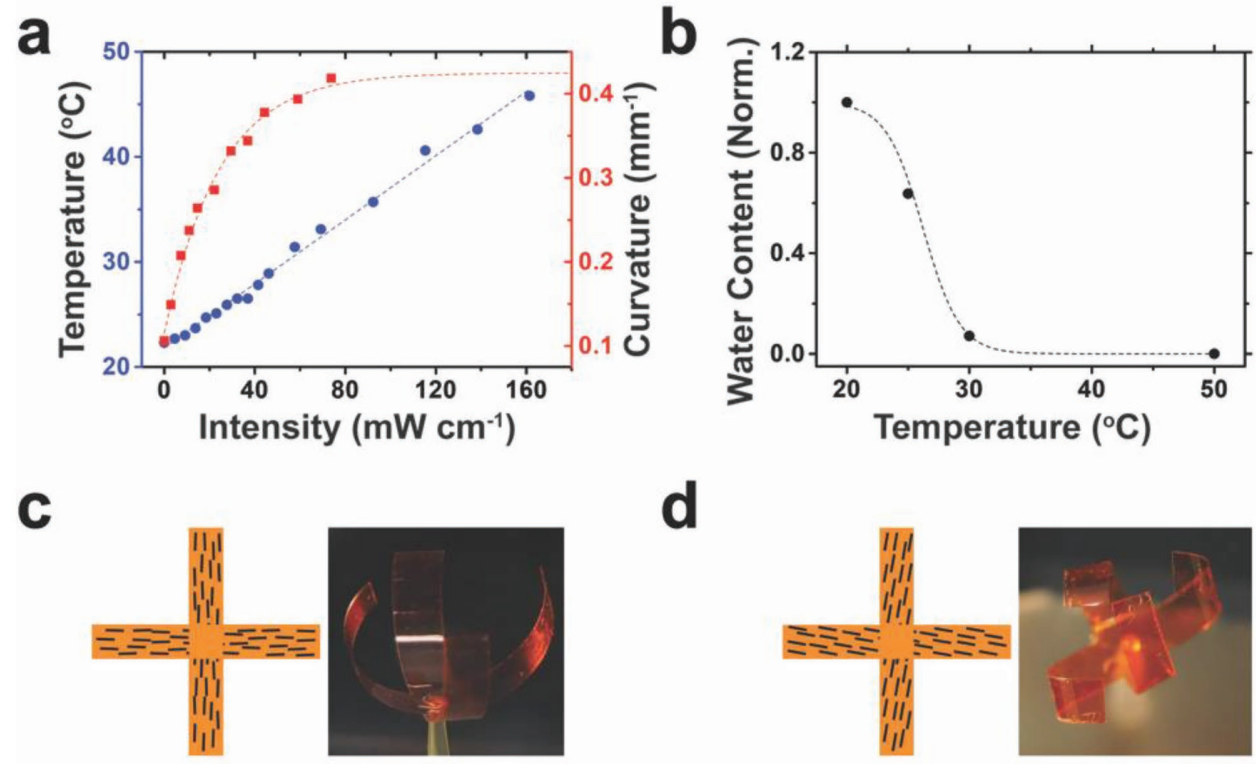

d
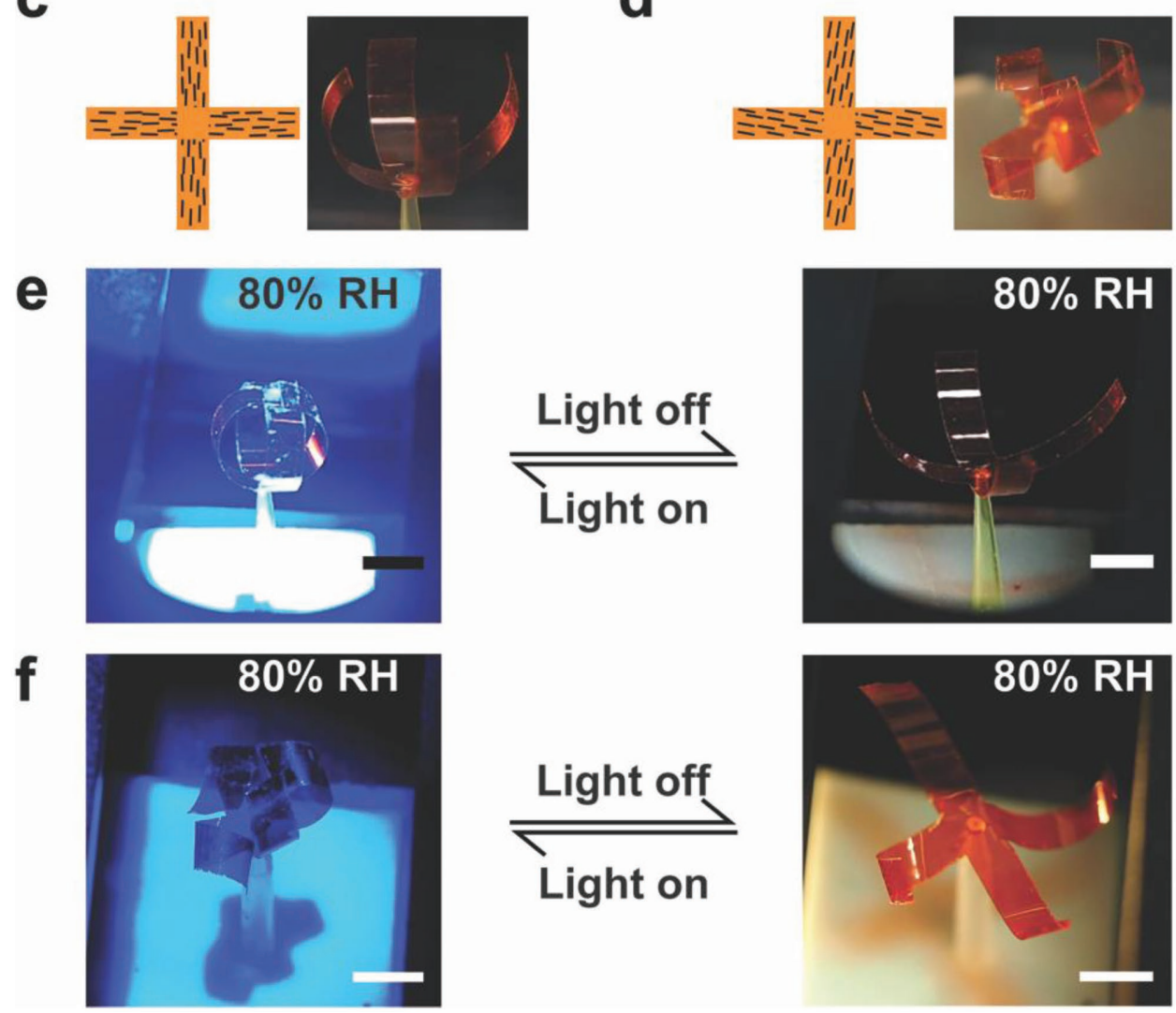

Figure 4. Demonstration of artificial nocturnal flower. a) Change in temperature and curvature of LCN strip upon illumination with increased light intensity. b) Plot of water loss upon increased temperature, as estimated from infrared spectroscopy. c,d) Representation of molecular alignment in four petals of monolithic LCN flowers and their corresponding initial shape under ambient conditions. In (c), the director on the planar side is parallel to the long axis of the petal, while in (d), the director has an offset of $10^{\circ}$ with respect to the long axis. e,f) Closure of LCN flower, in straight (e) and twisted $(f)$ ways, respectively, upon illumination with light, as dictated by their molecular alignment. All scale bars correspond to $5 \mathrm{~mm}$.

the night flowers, the nocturnal actuator remains closed at low RH or upon high light level, and only opens at high RH in the darkness (Figure 4e; Video S1, Supporting Information). To demonstrate the versatility of LCN materials compared to other stimuli-responsive materials in terms of controlling the directionality of deformation, a task very difficult to achieve in conventional hygroscopic materials, ${ }^{[43]}$ we made another nocturnal actuator having an offset angle of $10^{\circ}$ between director and the long axis of the flower petal (Figure 4d). Like some nocturnal flowers such as moon plant, ${ }^{[4]}$ this artificial "flower" opens and closes in a twisted manner (Figure 4f;
Video S2, Supporting Information). By varying the offset angle, the pitch of the twisting can be easily controlled, highlighting the strength of LCN actuators in devising biomimetic structures. Due to this advantage of LCN materials, even complex plant movements can be mimicked, providing a route for advanced and adaptive shape morphing.

In conclusion, we have demonstrated an artificial "nocturnal actuator" made of a monolithic multi-responsive liquid crystal network, which can mimic the opening and closing of night flowers. Similar to their natural counterparts, the movements of this LCN actuator are dictated by delicate interplay between 
light and RH. The demonstrated flower-like device closes when it is exposed to light or when the humidity level is low. It opens only in the dark, assisted by high humidity level in the environment. The method that drives the shape morphing, humiditygated photoactuation, is based on photothermally-induced water desorption from the LCN films. We foresee that the proposed bioinspired humidity- and light-responsive actuator, due to its fast response time and control over directionality, is promising for the realization of smart biomimetic systems and soft robots that can be manipulated remotely by low levels of light.

\section{Supporting Information}

Supporting Information is available from the Wiley Online Library or from the author.

\section{Acknowledgements}

A.P. gratefully acknowledges the financial support of the European Research Council (Starting Grant project PHOTOTUNE; Agreement No. 679646). O.W. thanks the Graduate School of Tampere University of Technology (TUT), as well as the International HR Services of TUT for funding a 6-month research internship to Technical University of Eindhoven, under the scheme "TUT on World Tour-2018." H.Z. thanks the Academy of Finland for a Postdoctoral Fellowship (decision number 316416). The authors thank Prof. Dirk Broer for inspiring discussions.

\section{Conflict of Interest}

The authors declare no conflict of interest.

\section{Keywords}

actuator, azobenzene, bioinspired, humidity, light, liquid crystal, multi-responsive

Received: September 14, 2018 Revised: October 17, 2018 Published online: November 12, 2018

[1] U. G. K. Wegst, H. Bai, E. Saiz, A. P. Tomsia, R. O. Ritchie, Nat. Mater. 2015, 14, 23.

[2] F. Xia, L. Jiang, Adv. Mater. 2008, 20, 2842.

[3] M. Liu, Y. Zheng, J. Zhai, L. Jiang, Acc. Chem. Res. 2010, 43, 368.

[4] Y. Zhao, F. Sakai, L. Su, Y. Liu, K. Wei, G. Chen, M. Jiang, Adv. Mater. 2013, 25, 5215 .

[5] S. Kim, C. Laschi, B. Trimmer, Trends Biotechnol. 2013, 31, 287.

[6] S. I. Rich, R. J. Wood, C. Majidi, Nat. Electron. 2018, 1, 102.

[7] L. Hines, K. Petersen, G. Z. Lum, M. Sitti, Adv. Mater. 2017, 29, 1603483.

[8] S. Maeda, Y. Hara, T. Sakai, R. Yoshida, S. Hashimoto, Adv. Mater. 2007, 19, 3480.

[9] X. He, M. Aizenberg, O. Kuksenok, L. D. Zarzar, A. Shastri, A. C. Balazs, J. Aizenberg, Nature 2012, 487, 214.

[10] H. Zeng, O. M. Wani, P. Wasylczyk, R. Kaczmarek, A. Priimagi, Adv. Mater. 2017, 29, 1701814
[11] K. Liu, X. Yao, L. Jiang, Chem. Soc. Rev. 2010, 39, 3240.

[12] L. F. Boesel, C. Greiner, E. Arzt, A. del Campo, Adv. Mater. 2010, 22, 2125.

[13] T.-S. Wong, S. H. Kang, S. K. Y. Tang, E. J. Smythe, B. D. Hatton, A. Grinthal, J. Aizenberg, Nature 2011, 477, 443.

[14] D. Roy, J. N. Cambre, B. S. Sumerlin, Prog. Polym. Sci. 2010, 35, 278.

[15] M. A. C. Stuart, W. T. S. Huck, J. Genzer, M. Müller, C. Ober, M. Stamm, G. B. Sukhorukov, I. Szleifer, V. V. Tsukruk, M. Urban, F. Winnik, S. Zauscher, I. Luzinov, S. Minko, Nat. Mater. 2010, 9, 101.

[16] I. Burgert, P. Fratzl, Philos. Trans. R. Soc., A 2009, 367, 1541.

[17] B. Mazzolai, L. Beccai, V. Mattoli, Front. Bioeng. Biotechnol. 2014, 2, 2.

[18] S. lamsaard, S. J. Aßhoff, B. Matt, T. Kudernac, J. J. L. M. Cornelissen, S. P. Fletcher, N. Katsonis, Nat. Chem. 2014, 6, 229.

[19] O. M. Wani, H. Zeng, A. Priimagi, Nat. Commun. 2017, 8, 15546.

[20] Y. Forterre, J. M. Skotheim, J. Dumais, L. Mahadevan, Nature 2005, $433,421$.

[21] B. S. Hill, G. P. Findlay, Q. Rev. Biophys 1981, 14, 173.

[22] W. G. Van Doorn, U. Van Meeteren, J. Exp. Bot. 2003, 54, 1801.

[23] L. Zhang, H. Liang, J. Jacob, P. Naumov, Nat. Commun. 2015, 6, 7429.

[24] L. Zhang, P. Naumov, Angew. Chem., Int. Ed. 2015, 54, 8642.

[25] H. Arazoe, D. Miyajima, K. Akaike, F. Araoka, E. Sato, T. Hikima, M. Kawamoto, T. Aida, Nat. Mater. 2016, 15, 1084.

[26] a) M. Ji, N. Jiang, J. Chang, J. Sun, Adv. Funct. Mater. 2014, 24, 5412. b) J. Mu, C. Hou, B. Zhu, H. Wang, Y. Li, Q. Zhang, Sci. Rep. 2015, 5, 9503.

[27] P. Zhou, L. Chen, L. Yao, M. Weng, W. Zhang, Nanoscale 2018, 10, 8422

[28] T. J. White, D. J. Broer, Nat. Mater. 2015, 14, 1087.

[29] C. Ohm, M. Brehmer, R. Zentel, Adv. Mater. 2010, 22, 3366.

[30] L. T. De Haan, A. P. H. J. Schenning, D. J. Broer, Polymer 2014, 55, 5885.

[31] O. M. Wani, H. Zeng, P. Wasylczyk, A. Priimagi, Adv. Opt. Mater. 2018, 6, 1700949 .

[32] H. Zeng, P. Wasylczyk, D. S. Wiersma, A. Priimagi, Adv. Mater. 2018, 30, 1703554.

[33] K. D. Harris, C. W. M. Bastiaansen, J. Lub, D. J. Broer, Nano Lett. 2005, 5, 1857.

[34] L. T. De Haan, J. M. N. N. Verjans, D. J. Broer, C. W. M. M. Bastiaansen, A. P. H. J. H. J. Schenning, J. Am. Chem. Soc. 2014, 136, 10585.

[35] A. Ryabchun, F. Lancia, A.-D. D. Nguindjel, N. Katsonis, Soft Matter 2017, 13, 8070 .

[36] Y. Liu, B. Xu, S. Sun, J. Wei, L. Wu, Y. Yu, Adv. Mater. 2017, 29, 1604792.

[37] K. D. Harris, C. W. M. Bastiaansen, D. J. Broer, J. Microelectromech. Syst. 2007, 16, 480.

[38] W. Nishiya, Y. Takanishi, J. Yamamoto, A. Yoshizawa, J. Mater. Chem. C 2014, 2, 3677.

[39] D. J. Broer, G. N. Mol, Polym. Eng. Sci. 1991, 31, 625.

[40] G. N. Mol, K. D. Harris, C. W. M. Bastiaansen, D. J. Broer, Adv. Funct. Mater. 2005, 15, 1155.

[41] Near-Infrared Spectroscopy: Principles, Instruments, Applications, (Eds: H. W. Siesler, Y. Ozaki, S. Kawata, H. M. Heise), Wiley-VCH, Weinheim, Germany 2002.

[42] F. Ridi, E. Fratini, S. Milani, P. Baglioni, J. Phys. Chem. B 2006, 110, 16326.

[43] L. Ionov, Mater. Today 2014, 17, 494.

[44] C. R. Gunn, Brittonia 1972, 24, 150. 